\title{
Padrão de política estatal em saúde e o sistema de assistência médica no Brasil atual*
}

\author{
The model of state health policy and the system of medical assistance adopted \\ in present-day Brazil
}

\author{
Marcos de Souza Queiroz"*, Ana Luíza Vianna**
}

\begin{abstract}
QUEIROZ, M. de S. \& VIANNA A. L. Padrão de política estatal em saúde c o sistema de assistência médica no Brasil atual. Rev. Saúde públ., S. Paulo, 26: 132-40, 1992. Pretende-se contribuir para a reflexão em torno da reforma sanitária em processo de implantação no Brasil. Defende-se o ponto de que para compreender os eventos mais recentes nessa área é necessário antes consolidar o referencial teórico que sustenta as conquistas já obtidas. Nesse sentido, a reforma sanitária é entendida como uma questão que transcende os aspectos referentes à administração e à gerência do sistema de saúde, uma vez que ela necessariamente envolve um redimensionamento crítico dos conccitos de saúde, de doença e, consequeentemente, da prática médica definida pclo paradigma mecanicista dominante da medicina. Com esta preocupação, são analisados e crilicados os eventos recentes que configuram o sistema de saúde brasilciro.
\end{abstract}

Descritores: Política de saúde. Sistema de Saúde. Programas nacionais de saúde.

\section{Introdução}

Embora já se tenha acumulado conhecimento sociológico expressivo sobre o sistema c a política de saúde no Brasil, pouco se tem avcntado sobre un problema cujos contornos se mostram cada vez mais claros, ou seja, a inadequação do paradigma médico mecanicista dominante bascado no hospital para definir saúde e doença e a conseqüente necessidade de se promover uma concepção social da medicina. $\mathrm{O}$ presente artigo pretende retomar este tema que se iniciou de modo promissor com a tese de Arouca (1975), mas que não chegou a ser devidamente aprofundado diante do desenrolar dos eventos quc atualmente configuram o sistcma de saúde brasilciro.

\section{A Intervenção Estatal da Saúde no Brasil}

Como é de conhecimento geral, o processo de

* Trabalho realizado com apoio financeiro do Conselho $\mathrm{Na}$ cional de Desenvolvimento Científico e T'ecrológico (CNPq). Processo n $n^{2} 30.1966 / 83-4$.

* Núcleo de Estudos de Políticas Públicas (NEPlP) UNICAMP - Campinas, SP - Brasil.

Separatas/Reprints: M. de S. Quciroz - Caixa Postal 6166 13081-970 - Campinas, SP - Brasil.

Publicação financiada pela FAPESP. Processo Saúde Coletiva 91/49 94-0. intervenção estatal na árca da saúde no Brasil ocorreu $\mathrm{cm}$ três períodos, caracterizando três padroes distintos: o dos governos populistas, o dos governos burocrálico-autoritários e o que corresponde à transição democrática (Teixcira ${ }^{11}, 1989$ ).

Os governos populistas imprimiram um padrão de política social caracterizada por um corporativismo fragmentado que, através das Caixas de Pensão e Aposentadoria, dividia a classe trabalhadora em várias categorias com privilégios diferenciais.

O período autorilário-militar caraclerizou-se por uma grande centralização política, financcira e operacional de todo o sistema de saúde através do INAMPS que, pelo repasse de verbas ao setor privado, passou a promover serviço médico a toda a população trabalhadora afiliada ao sistema. Esta ampliação do poder de intervenção estatal permitiu um enorme crescimento do setor privado, provedor direto ou indireto de equipamentos e de serviços médicos, propiciando a mercantilização c a cmpresarização da medicina numa escala nunca antes atingida. Tecnologia de ponta passou a ser introduzida no tratamento médico oferecido à população trabalhadora, ao mesmo lempo $\mathrm{cm}$ que a rede básica de serviços de saúde, encarregada do controle das grandes endemias c da saúde pública em geral, se detcriorava.

O crescimento do setor saúde engendrado por este sistema foi descontrolado, sem conseguir desenvolver sistemas de referĉncia e mecanismos de integração de scus diferentes níveis, gerando com 
isso grande desperdício de recursos. Como consequêencia, o sistema tornou-se ineficiente e ineficaz no sentido de promover uma melhora nos níveis de saúde da população.

O período de redemocratização que começou a ocorrer ao final dos anos 70 , tendo herdado a massa falida de um Estado em processo de desintegração, caracterizou-se na área da saúde por um repensar de todo o sistema, tendo em vista o propósito de se estabelecer uma reforma sanitária que efetivamente pudesse oferecer melhores condições de saúde. Neste novo espaço, a legitimização do Estado passou a depender cada vez mais da satisfação de reivindicações e do preenchimento de valores provenientes da sociedade civil, $\mathrm{cm}$ detrimento da burocracia e de interesses corporativos de geração de lucros.

Nos anos 80 , com a crise econômico-financcira do país em geral e a crise da previdencia social em particular, tanto o planejamento como a gestão do sistema de saúde tornaram-se impraticáveis. $O$ descontrole revelou-se na deterioração de um sistema que, ao servir muito mais aos propósitos das atividades burocráticas e às necessidades lucrativas das empresas do que as necessidades de saúde da população, tornou-se corrupto e corruptor.

O colapso do sistema de saúde brasilciro e a necessidade de uma reforma profunda em seu interior foi um diagnóstico consensual entre a grande maioria dos técnicos do setor. No entanto, se houve convergência neste diagnóstico mais amplo, quando se procurou dar mais especificidade ao problema, ficaram caracterizadas duas propostas divergentes: uma que pretendeu dimensionar a crise exclusivamente sob o ponto de vista gerencial e administrativo; e outra que, além deste aspecto, procurou enfatizar a inadequação do paradigma* hegemônico da medicina no sentido de focalizar os problemas modernos de saúde e doença. Para o primeiro ponto de vista, o problema da saúde e da medicina reside muito mais na irracionalidade operacional do sistema do que em qualquer outro fator. Para o segundo, o qual procurar-sc-á defender no presente artigo, a racionalização opcrativa do sistema de saúde seria insuficiente para resolver o problema, uma vez que cle reside numa instância mais profunda ao nível do "olhar" médico desfocalizado dos verdadeiros problemas de saúde e doença que acometem a sociedade moderna.

* O termo paradigma é entendido ao longo deste arigo no sentido empregado por Khun ${ }^{6}$ (1975), ou seja, como um mapa que governa a percepção do cientista a ponto de impedir que ele procure por fatos e perspectivas novos. Desse modo, a ciência procura referendar o já sabido e, apenas em ocasiōes especiais sub a influência de fatores sócio-culturais e ćconômicos, ela se toma inovadora.

\section{A Crise da Medicina e do Setor Saúde em Escala Mundial}

A crise do setor saúde não é um fenômeno exclusivamente brasileiro. Em paises centrais, ela ocorreu gencralizadamente no interior de duas crises mais amplas: a do estado de bem-estar social e a do paradigma mecanicista da medicina curativa.

Ao se dar conta da impossibilidade do Estado continuar financiando os serviços públicos essenciais e, dentre eles a oferta sanitária, os países centrais procuraram rapidamente promover um novo modelo assistencial e institucional e um novo padrão de financiamento. Os recursos limitados para financiar os programas sociais, a consumir cada vez mais esforços e mcios financeiros, exigiram uma melhor racionalização dos custos compreendendo uma melhoria no nível de eficiência e elelividade dos serviços ofertados.

Como lembra Vianna ${ }^{12}$ (1990), as políticas de contenção da demanda e de redução da oferta sanitária foram implantadas, por exemplo, nos programas "Medicare" e "Medicaid", nos Estados Unidos dos anos 70 (e, posteriormente, de um modo muito mais drástico, no governo Reagan anos 80); na reorganização do "National Health Scrvice" inglês em 1974 (e mais recentemente no governo Thatcher - anos 80); na reorganização do serviço de saúde ocorrida na Alemanha, em 1977, e no da Itália, a partir de 1978, e em muitos outros paíscs. A maior eficiência e efctividade propostas nesses e $\mathrm{cm}$ outros países centrais surgiram, portanto, como uma necessidade imperativa de manter as contas públicas sob controle e também como a única alternativa para a manutenção do Estado na condução de políticas sociais e a construção de legitimidade por parte dos governos.

Para dar uma dimensão numérica à impossibilidade de manter o sistema de saúde como vinha ocorrendo, basta citar que há trinta anos os gastos totais em saúde (como proporção do produto nacional bruto), da maioria destes países, era de cerca de $4 \%$. Hoje, após um periodo de grande crescimento econômico, a mesma proporção chega, em média, a cerca de $10 \%$, com tendência a um crescimento cada vez maior se forem mantidas as condições de funcionamento anterior à reorganização do sistema.

Ao lado desta crise de financiamento do sistema, um outro falo se destaca rclativo à completa ausência de evidências a comprovar que esse aumento brutal nos gastos com este tipo de medicina tenha revertido $\mathrm{em}$ melhores níveis de saúde para a população (Ehrenreich ${ }^{4}, 1978$; Powles 9 , 1973). A conclusão mais importante a se depreender desse argumento é que, num nivel mais profundo, 
o problema da medicina e da saúde envolve uma dimensão social que, por ser muito mais ampla, não pode ser reduzida a uma questão exclusivamente administrativa ou financeira.

Em realidade, a incapacidade da saúde humana responder favoravelmente a um maior investimento de esforços e de recursos financeiros nesta árca mostra que a natureza do problema reside muito mais numa ordem conceitual e epistemológica, presentes numa definição limitada de saúde e doença do que em qualquer outro fator. Esta definição percebe saúde como uma simples ausência de doença e esta como um problema individual de ordem exclusivamente biológica.

Reverter o paradigma dominante no campo médico só pode significar que as causas mais profundas que determinam a saúde $\mathrm{e}$ a doença encontram-se assentadas no nível social. Embora tendo as suas origens na segunda metade do século XIX (tendo Virchow na Alemanha Bismarkiana como expoente), esta idéia foi obscurecida (principalmente a partir do sucesso de Pastcur em provar a existência de microorganismos que contaminam o meio orgânico) por uma concepção biologicistá e mecanicista do ser humano, que concebe a doença como uma agressão mono-causal externa. Nesta concepção, a doença é vista como um problema individual, sendo a cura uma questāo de mera intervenção mecânica no nível biológico.

A reintrodução da questão social na determinação da saúde e da doença é, portanto, um fenômeno recente que teve um desenvolvimento maior a partir da segunda melade deste século. Este novo "olhar" para a questão da saúde e da doença recolocou a comunidade e seu mcio ambiente físico e social numa posição central. Se, no entanto, a hegemonia desta nova concepção é rclativamente simples de ser reivindicada no campo científico e ideológico, na prática, ela depende de muitos outros fatores de ordem sociocconômica, política e cultural.

Esta reversão deve, no entanto, ser inevitável simplesmente porque não há outro meio possível de contornar a crise que envolve não só o sistema de saúde como a própria medicina enquanto ciência. Por esse motivo, a proposta de um novo centro de gravidade para a medicina bascado na saúde e no bem-estar de uma comunidade e não só na doença que se manifesta em nívcl biológico, é válida para qualquer tipo de contexto, seja cle relacionado com países desenvolvidos ou subdesenvolvidos, industrializados ou rurais e de economia de mercado ou planejada.

As tentativas mais expressivas de mostrar a inadequação do paradigma dominante da medicina moderna em conceptualizar o significado de saúde e de doença foram realizadas originalmentc por autores radicais, como, por exemplo, Illich 5 (1975) que, em geral, situavam-se numa posição marginal tanto na área acadêmica como na institucional. A Organização Mundial da Saúde (OMS), em seguida, dcfendeu na Conferência Internacional de Alma $\mathrm{Ata}^{2}$ a necessidade de se promover uma mudança radical na percepção médica de saúde e de doença. A OMS produziu ainda um relatório, publicado por $\mathrm{O}^{\prime} \mathrm{Neal}^{8}$ (1983), que pode ser considerado um marco em que se estabelece de um modo coerente as bases fundamentais de um paradigma social da medicina.

Na conferência de Alma Ata, a ênfase recaiu na operacionalização do conceito de saúde expresso na constituição da OMS, ou seja, um estado de completo bem-estar físico, mental e social. Como um direito inalienável de todo o indivíduo, os serviços de saúde devem pressupor uma cobertura universalizada, hicrarquizada, integrada, regionalizada $\mathrm{c}$ descentralizada. $\mathrm{O}$ aspecto revolucionário $\mathrm{cm}$ que se assenta tal proposta é a percepção da saúde e da doença como numa dimensão que vai além do organismo biológico individual e penetra na estrutura e organização sociais. Nesse sentido, um papel especial é dedicado à participação e ao controle da comunidade no planejamento, organização e operação desses serviços.

No relatório de 1983, esta postura é desenvolvida mais profundamente, sendo o paradigma biológico mecanicista hegemônico conferido por todos os lados pelo novo paradigma social da medicina. Não se trata evidentemente de abolir a medicina curativa hospitalar centrada no aspecto biológico individual. $O$ que se propõe é limitar este aspecto de um modo tal que ele deixe de ser dominante e passe a ser subordinado a uma dimensão social maior que o envolve e o controla. Trata-se, portanto, não só de uma solução econômica à crise fïnanceira da medicina como também uma solução epistemiológica à crise cientílica da medicina moderna.

A tese de que a manutenção do modelo curativo centrado na biologia individual e no hospital não é adequada para compreender, interpretar, explicar e, muito menos, resolver amplos aspectos relacionados com saúde e docnça é explicada pela hiperdimensionalizaçāo de uma medicina fragmentada $\mathrm{e}$ de um sistema de saúde desintegrado, ambos inteiramente dominados por especialistas dentro de um paradigma que tem como referência maior a influĉncia mecanicista e biologicista própria de um posilivismo sem qualquer consideração à dimensão social. Este paradigma levou ainda a um desenvolvimento tecnológico descontrolado resultando num alto custo financeiro e num modelo inadcquado para resolver a maioria dos problemas que alligem a comunidade. 
Os efeitos adversos produzidos por este tipo de medicina chegam, na análise da OMS, a pesar mais do que os benefícios. Entre estes efeitos podem ser citadas as infecçōes hospitalares, as scqüelas provenientes de drogas e cirurgias e a redução da autoconfiança da população em administrar a sua vida no sentido de promover a própria saúde.

É um fato inegável que, por outro lado, a tecnologia desenvolvida por este tipo de medicina pouco pode fazer diante dos principais problemas de saúde de uma sociedade moderna, que já tenha conquistado o flagelo das doenças infecciosas. $O$ consumo descontrolado de tabaco, álcool, drogas e medicamentos, a dieta desequilibrada e inadequada, a ocupação sedentária, a violência e o estresse urbanos, os desequilíbrios mentais, os hábitos sexuais perigosos, os acidentes de automóvel e vários outros fatores que têm a sua origem no modo de vida não podem ser controlados ou sequer dimensionados pela tecnologia disponivel num hospital. Deslocada da comunidade e de scus problemas especílicos, a medicina hospitalar focaliza e trata apenas problemas que se tornaram extremamente sérios e exigem intervenções drásticas no organismo biológico humano tomado isoladamente. Como conseqüência, diante do hiperdimensionamento do hospital, as causas profundas das doenças, que geralmente têm origem no modo como a sociedade interage com o meio ambiente e, em seu interior, os indivíduos interagem entre si, são deixadas inalteradas. Alocar para este âmbito a maior parte de todos os recursos disponiveis para a saúde é, portanto, uma medida inadequada se não irracional diante do propósito de se elevar o nível de saúde de uma população.

Já a medicina social aparece como uma dimensão capaz de introduzir uma concepção muito mais profunda que permite uma maior compreensão dos mecanismos que promovem a doença e a cura. Um dos aspectos centrais desse novo paradigma é a ênfase na saúde e no controle desta pela comunidade ao invés da ênfase na doença e no seu controle pelo médico. Para que este objetivo seja alcançado, a descentralização dos scrviços e o scu controle pela comunidade são considerados prioritários pela OMS.

De um modo geral, com diferentes graus de profundidade, houve tentativas nos paises centrais de absorver esta nova proposta, cmbora scja ainda muito cedo para se dizer que a hegemonia de um paradigma baseado no social estcja, em algum lugar, perto de acontecer.

\section{A Medicina Preventiva e Social: A Emergência noBrasil de um Novo Paradigma da Medicina}

Seguindo a recomendação da Organização Panamericana da Saúde, as maiores Universidades brasileiras criaram os Departamentos de Medicina Preventiva e Social que desenvolveram um pensamento crítico da Saúde (principalmente pelo Centro Brasileiro de Estudos da Saúde) e propostas alternativas para a medicina que ganharam corpo com a implantação de vários programas experimentais alternativos dirigidos principalmente às populações pobres. Somarriba ${ }^{10}$ (1978) relata com muita sensibilidade uma dessas experiências conduzidas em Minas Gerais que, como muitas outras, serviu para acumular conhecimentos práticos sobre uma perspectiva teórica que já apresentava um certo desenvolvimento.

A tese de Arouca $^{1}$ (1975) e o livro de Donnangelo e Pereira ${ }^{3}$ (1976) constituíram marcos pioneiros no estabelecimento do paradigma social da medicina que tem como fulcro o estabelecimento do método histórico-sociológico-cultural na apreensão do campo da Saúde Coletiva. Ao constatarem que esta perspectiva proporciona uma dimensão incomparavelmente mais ampla e profunda sobre saúde, doença e cura do que o referencial positivista, esses autores reivindicam para ela uma hegemonia científica $c$ operacional em relação à medicina curativa bascada no hospital.

A emergência do paradigma preventivista e social apontando para a crise do hiperdimensionamento da medicina clínica curativa veio no Brasil acompanhada por uma crise financeira do Estado ainda muito mais profunda do que a ocorrida nos países centrais. Se, no entanto, estes últimos responderam de um modo rápido à crise do sistema de saúde, ainda que neles a medicina curativa continue a ser superdimensionada em relação à medicina preventiva e social, o Brasil tem demonstrado uma lentidão muito maior nesse sentido. Isso constitui um verdadeiro paradoxo se for considerado que, neste país, a necessidade de uma reforma profunda no sistema de saúde se mostra muito mais urgentc, diante da escassez de recursos e do baixo nível de saúde da população.

É um fato inquestionável que, no plano das idéias, o Brasil contribuiu para o campo de saúde colcliva com valiosa reflexão crítica necessária para a construção de um novo paradigma na área da medicina e saúde. Ao lado do processo de democratização expcrimentado pelo país, houve avanço considerável no estabelecimento de um certo consenso $\mathrm{cm}$ como equacionar os principais problemas nesta área. A criação de um sistema de saúde numa ordem hicrarquizada, descentralizada e universalizada, apesar da lentidão com que se tenta resolver scus obstáculos, é uma expressão importante deste consenso.

Toda uma década foi neccssária para que o problema fosse devidamente focalizado e enquadrado tendo em vista um plano prático de ação. Após as 
tentativas de implementação dos projetos PIASS, PREV-SAÚDE E CONASP (planos que propunham a implantação de serviços básicos de saúde como porta de entrada para um sistema mais abrangente, racionalizando, assim, o planejamento e gerenciamento de recursos e práticas de saúde), o ano de 1983 assistiu aos primeiros convênios das Açōes Integradas de Saúde (AIS), envolvendo o Ministério da Saúde, o Ministério da Previdência e Assistência Social e as secretarias estaduais e municipais de saúde.

Com as AIS, algumas secretarias de saúde de Estado e de municípios tiveram a oportunidade de efetivamente participar no planejamento e na administração do setor saúde como um todo, mediante a criação dos órgãos colegiados gestores, CIS (Conselho Interinstitucional de Saúde), CRIS (Conselho Regional Interinstitucional de Saúde) e CIMS (Conselho Interinstitucional Municipal da Saúde).

Em março de 1986, o Ministério da Saúde promoveu a oilava Conferência Nacional de Saúde, na qual teve lugar um amplo processo de discussão sobre os principais problemas de gcrenciamento, controle e administração de saúde da população brasileira, envolvendo todos os sctores organizados da sociedade. Mais do que uma simples discussão, no entanto, as diretrizes emanadas desta Conferência serviram como referência e base para o Decreto Presidencial que criou o Sistema Unificado e Descentralizado de Saúde (SUDS), em junho de 1987.

O SUDS promoveu um efetivo processo de transferência de recursos matcriais, humanos e financeiros para os Estados e, atravćs destes, para os municípios, dentro do princípio (necessário à distribuição regional de renda) de complementariedade desses três niveis federativos. Nesse esquema, o município representa uma instância integradora de todo o sistema de saúde, contribuindo decisivamente para as funções de organização, gestão, execução e fiscalização das ações e scrviços disponíveis à comunidade.

A transferência de um considerável grau de responsabilidade ao poder local pretende promover uma maior racionalidade operativa ao sistema, dentro de um princípio mais justo c equiânime que permite a cada indivíduo o dircito ao acesso a todos os níveis de assistência, como também um controle pela população (pela sua participaçāo nas instâncias colegiadas de decisão), no sentido de promover uma mclhor eficácia e cficiência dos mesmos. Além disso, o processo de descentralização permite tambćm adcquar o sistema a cada uma das muitas realidades regionais de um país de dimensões continentais como o Brasil.

Todo esse processo culmina com a promul- gação da nova constituição brasileira em 1988, em que fica explicitada a obrigação do município, com a cooperação técnica e financeira da União e do Estado, em providenciar serviços de atendimento à saúde de toda a população através de um sistema único de saúde que passou a ser denominado SUS. No centro desse sistema encontra-se uma rede básica pública de serviços de saúde que atua fora da lógica de mercado, articulando as demandas por serviços médicos com o conjunto dos serviços de maior complexidade, de retaguarda. Nesse sistema, é admissivel haver uma composição ou associação com o setor privado, o qual não se cogita erradicar.

Com isso, pretendeu-se dar um sentido orgânico e hicrarquizado a um conjunto de unidades de saúde que antes eram totalmente divorciadas entre si. Nesse sistema, organizado e administrado em nivel local pelas várias prefeituras, a tradicional dicotomia entre medicina preventiva e medicina curativa deveria deixar de existir, uma vez que o significado de saúde deveria passar a ser muito mais centrado nos problemas vividos pela comunidade.

Embora a área da saúde no Brasil tenha embarcado numa reforma que provavelmente será irreversivel, uma vcz que tende a imprimir maior racionalidade, não se pode dizer que o seu desenvolvimento scja rápido e tranqüilo. Os riscos e os desafios são inúmcros, principalmente nas regiōes mais atrasadas, onde talvez o maior obstáculo seja o precário nível político traduzido pelo clientelismo ou pcla corrupção pura e simples.

Embora mais racional na teoria, a implementação prática dessa nova forma administrativa na árca da saúde pode tornar-se dificil, dependendo de circunstâncias locais imprevisívcis para um plano de naturcza macropolítica. A disposição de grupos representando certos interesses econômicos ou políticos ou mesmo a iniciativa individual de políticas locais no sentido de promovê-la, manipulá-la em favor de outros interesses ou mesmo boicotá-la podem constituir fatores decisivos para o seu sucesso.

A manipulação do plano pclas forças políticas e econômicas locais para servir a propósitos diferentes de sua naturcza deve também ser considerada um perigo constantc a ameaçar a sua integridade, principalmente se for levado em conta a fraqueza institucional dos mecanismos de controle do mesmo. Enquanto um plano que, entre várias outras medidas, visa a impedir a transferência de recursos do sctor público para o privado, não é muito provável que ele venha a receber apoio de amplos setores da socicdade, inclusive o de uma significativa proporção de médicos. Tudo indica, portanto, que o scu sucesso irá depender em grande medida do grau de maturidade cultural e política que o país vier a demonstrar. 
Entre os problemas encontrados, destacam-se ainda aqueles referentes a tornar um sistema múltiplo $\mathrm{em}$ sistema único de saúde controlado $\mathrm{e}$ administrado pelo poder local. A transferência de recursos para os municípios tem permitido que estes exerçam uma influência cada vez maior na área, embora ainda não possam controlar todo o sistema. Isso ocorre porque vários aspectos da antiga multiplicidade administrativa ainda pcrsistem como, por exemplo, o fato de haver funcionários contratados por instâncias estaduais ou fedcrais que atuam junto com os da própria prefcitura. É evidente que este fato, à medida que implica $\mathrm{cm}$ salários e regimes de trabalho diferenciados para a mesma função, prejudica a integração do serviço. Além disso, os convênios que, com o repasse financeiro, permitem a integração e o controle do serviço a nível local, não significam propriamente um modo seguro e estável para a continuidade e desenvolvimento do processo.

Apesar de todos os problemas e obstáculos, a experiência desta reforma administrativa chegou a apresentar algum sucesso no Estado de São Paulo. Calcado na experiência de descentralização (ou descontração, para ser mais cxato) administrativa do governo Montoro, houve neste Estado uma efctiva transferência de recursos para a área da saúde de um grande número de prefeituras. Foi vital para este relativo sucesso, a disposição do Estado e das Prefeituras de aumentar considcravelmente o orçamento para a saúde.

A reorganização administrativa da árca da saúde, tendo como base os princípios expostos acima são, portanto, indispensáveis para tornar o paradigma preventivista (que traz em si uma nova concepção de saúde e de doença) hegemônico.

No entanto, ela não é suficiente para que uma medicina social efetivamente controlada pela comunidade apresente condições de emergir. $\mathrm{O}$ desenrolar mais recente dos fatos sugere efclivamente que a municipalização dos scrviços de saúde está se mostrando não só incapaz de promover o novo paradigma, como introduz, $\mathrm{cm}$ alguns aspectos, um reforço adicional para preservar o domínio da velha concepção positivista de saúde, doença e cura. Neste contexto, a municipalização dos serviços de saúde surgiria apenas como uma nova roupagem que permitiria ao velho paradigma condições de continuar exercendo a sua hegemonia.

\section{Discussão: Uma Tentativa de Avaliação do Sistema de Saúde Atual}

A avaliação do sistema de Saúde atual pode ser iniciada a partir da análise de sua regulamentação, consubstanciada na elaboração da Lei Orgânica da
Saúde, e de scus desdobramentos em Portarias, Resoluçōes e Normas Opcracionais.

A implementação do SUS, após sua promulgação pela Constiluição de 1988, rêz-se através da elaboração de Lei Orgânica aprovada pelo Congresso Nacional, como fruto do Relatório do Deputado Geraldo Alckmin na Comissão de Assistência, Previdência e Sáude e dos Projetos de Lei do Deputado Raimundo Bezerra (1989) e do próprio Execulivo (1989). A Lei Orgânica foi finalmente aprovada pelo Congresso e sancionada com vários velos pelo Presidente da República (8080/90). Em dezembro de 1990, no entanto, o Poder Executivo envia ao Congresso novo Projeto de Lei $(8142 / 90)$ que (após absorver propostas dé vários segmentos envolvidos no setor) foi, de certa forma, um tentativa de reparar os problemas gerados pelos vetos presidenciais ao Projeto original.

Duas ordens de problemas se impuseram no centro das discussõcs sobre a implementação do SUS: a definição das instâncias gestoras do sistema de Saúde e a adoção de critćrios para os repasses dos recursos do Fundo Nacional de Saúde para os Estados e Municípios. O Projeto original previa a existência de Conselhos de Saúde, envolvendo a participação dos diferentes agentes com auribuição de formular, acompanhar, plancjar e fiscalizar a implementação da política de saúde. A Lei 8080/90 veta a existência de Conselhos, c a Lei $8142 / 90$ pre$v \hat{e}$, não só o Consclho, como designa que a participação entre burocracia governamental/prestadores de serviços/profissionais do setor de saúde/usuários será paritária. A Norma Opcracional definiu, ainda, como atribuiçoes dos Consclhos de Saúdc, a formulação de estratćgias e o controle da execução da política de saúde na sua instância correspondente, inclusive nos aspectos econômicos e financeiros. É também atribuição dos Consclhos a aprovação dos Planos de Saúde em cada esfera de sua atuação, bem como a fiscalização da movimentação dos recursos repassados às secretarias estaduais e/ou municipais e/ou fundos de saúde.

Quanto à transferência de recursos, a Lei original previu o repassc automático, baseado nos seguintes critćrios: população, perfil epidemiológíco, gasto proporcional $\mathrm{em}$ saúde dos Estados c Municípios, capacidade instalada dos serviços, descmpenho técnico/financciro e econômico do pcríodo anterior e plano quinqüenal de investimento. A Lci definia um tcto mínimo para o repasse aos Municípios (não inferior a $45 \%$ do Fundo de Saúde) e a abolição da forma Convênio. Os vetos presidenciais extinguiram o repasse automático, o tcto mínimo, a abolição dos Convênios e definiram os seguintes critérios para repasse: $50 \%$ dos recursos do Fundo de Saúde, perfís demográficos e epidemiológicos, característica da 
rede de saúde, desempenho do sistema e níveis de participação do setor Saúde nos orçamentos estaduais. Os outros $50 \%$ seriam negociados segundo Programas e Projetos.

O último projeto de Lei (8142/90), através de regulamentação*, dcixou o repasse automático em aberto e designou para o ano de 1991 que as transferências sejam feitas com base no critério demográfico, tendo ainda como parâmetro de reajuste a unidade de cobertura ambulatorial (UCA). $\mathrm{O}$ teto mínimo para o repasse ao Município foi expandido para $70 \%$ do Fundo de Saúde, sendo que a base jurídica das transferências deverão ser os Convênios. A regulamentação da Lei define ainda as seguintes exigências para o recebimento dos recursos pelos Estados e Municípios: formação de conselhos de saúde (com representação paritária); fundos de saúde e planos de saúde aprovados pelo conselho e refcrendado por autoridade do poder executivo; programação e orçamentação da saúdc; relatório de gestão local; e constituição de comissão de elaboração do plano de carreiras, cargos c salários, com prazo de 2 anos para implemenlação.

As novas regulamentações defincm, ainda, o pagamento da cobcrtura ambulatorial pública e privada com base em procedimentos diagnósticos (atos médicos), e o repasse direto para municípios e prestadores privados.

Os problemas que tais resoluções trazem ao sistema de saúde são vários, sendo que num âmbito mais abrangente ele impõe obstáculos adicionais significativos à hegemonia do paradigma social da medicina e da saúde. Entre os principais problemas específicos, é possível destacar os seguintes:

1) O sistema antigo com base nos termos aditivos ao convênio SUDS previa o repasse mensal para o custeio dos centros ambulatoriais municipalizados. Agora esse recurso agrupa-se na $\mathrm{UCA} / \mathrm{mês}$, do qual deduz-se as guias de autorização de pagamentos dos centros ambulatoriais públicos e privados**. O pagamento por produção na rede ambulatorial pública introduz uma série de inconvenientes, desde a falta de recursos

* Pontarias 1481 de $31 / 12 / 90 ; 15,16,17,18,20$ de $8 / 1 /$ 91: Resoluçāo 250 de $7 / 1 / 91$ e Noma Operacional Básica $1 / 91$ de $7 / 1 / 91$.

* A fórmula do repasse é a seguinte:

População do Estado X UCA = Repasse

Repasse: 12 = Repasse Mensal

Repasse - Guja de autorização de Pagamento (Público + Privado) $=Y$

$10 \%$ de $\mathrm{Y}=$ Repasse para a Secretaria Estadual para as açōes de vigilância

$Y-10 \%(Y)=Z$

$\mathrm{z}:$ População do Estado $=\mathrm{W}$

W x População do(s) Município(s) = Repasse Municipal para os gastos com programas especiais (a rede pública desenha uma série de atividades agrupadas por programas visando ao atendimento de populações de risco) como os de tuberculose, hanseníase, AIDS, hemoterapia, e outras ações tipo educação em saúde e ações coletivas. Acrescente-se ainda a falta de tradição do setor público em contabilizar as ações curativas e preventivas da mesma forma que o setor privado, o que significa dizcr que as açōes públicas em saúde fo$\mathrm{gem}$ da regra oferta/cadastramento e produção/ faturamento de atos mćdicos;

2) o repasse direto para municípios e setor privado esvazia os scrviços de avaliação e controle das instâncias regionais do Estado, pois as fichas de atendimento ambulatorial não deverão mais passar por estas instâncias;

3) o repasse através de guia de autorização de pagamento(s) desarticula o sistema adotado no Estado de São Paulo, justamente onde o processo de municipalização é mais desenvolvido. Este procedimento não ć adotado neste Estado desde 1988 quando o pagamento passou a scr peça integrante do sistema orçamentário (auravćs de programação financeira mensal com empenho após demonstração de existência de recurso), sendo todo o sistema contabilizado nos moldes da administração financeira estadual;

4) os recursos a serem repassados em duodécimos aos Estados c Municípios serão resultados da subtração dos gastos com os prestadores privados. Isso significa que os serviços privados serão privilegiados;

5) cm estudo realizado pela Secretaria de Saúde do Estado de São Paulo há demonstração de que os municípios grandes serão agraciados com recursos que superam a antiga lógica de pagamento por custeio, ao mesmo tempo que os municípios pequenos scrão prejudicados.

Pode-se dizer a parlir dos problemas levantados acima que as bases de sustentação do sistema passam a ser o setor privado especializado e as prefeituras de grande porte, introduzindo um elemento de "inampização" na municipalização, sendo que a saúde colctiva preventiva fica mais uma vez à mercê dos insuficientes recursos oriundos dos orçamentos estaduais e municipais.

A implementação do SUS, mesmo no Estado de Sa Paulo, onde seu desenvolvimento foi maior, apresentava, antes mesmo dessas novas resoluções, uma sćrie de problemas decorrentes da incapacidade do nivel regional $\mathrm{cm}$ gerenciar 0 novo modelo de Saúde. As novas medidas de municipalização accleraram o processo de desajuste dos nívcis regionais, pois quando o município é economicamente forte e possui alta capacidade de resolutividade, dificilmente estará estimulado a 
promover um entrosamento satisfatório com o nivel regional.

De um modo geral, ao se tornarem um dos cixos da implementação da política de saúde, os municípios distorceram o modelo assistencial $\mathrm{em}$ favor do aumento da cobcrura do sistcma consubstanciado no pronto atendimento. Este procedimento medicalizante já impedia a adequação deste modelo assistencial com o paradigma social da medicina.

As atuais resoluções só virão confirmar tal tcndência à medida que o pagamento por produção, tanto para o setor público como para o sctor privado, induzirão a um desvio produtivista no sistema e um afastamento das questoes rclativas à qualidade e ao tipo de assistência prestada.

Quanto às instâncias gestoras, a tendência cxposta no Estado de São Paulo cra de domínio do poder local (prefeituras) na atuação c composição das comissões interinstitucionais, sendo que a instância regional (CRIS) atuava mais como neutralizadora dos conflitos municipais, decorrentes, em sua maior partc, das diferenças das faixas salariais adotadas pelos municípios, $c$ das chamadas invasões de áreas (demanda por serviços de outro município). O princípio de paridade nos Conselhos de Saúde talvez neutralize a presença hegemônica do poder local, porém são inúmeras as formas que as prefeituras terão para impedir uma participação que oponha às diretrizes de suas politicas locais, sem contar com o baixo grau de organização da população no que se refere às prerrogativas de sua cidadania social.

A avaliação atual do SUS evidencia um reforço muito grande dos municípios na implementação da assistência à saúde, sendo que os mesmos evoluíram de simples expectadores a prestadores de serviços. Não obstante, eles não podem ainda ser vistos como co-partícipes do sistema único, mas apenas de como ofertantes-contratidos, a partir da forma de pagamento definida pelas novas resoluções. Tal configuração constitui um obstáculo de dimensões consideráveis ao poder de decisão da comunidade de promover saúde; ao mesmo tempo, ela dificulta a relocação da dimensão biológica da medicina num âmbito dependente de objetivos sociais.

Além disso, o papel de contato permanente com a comunidade, atribuído à Rede Básica de Serviços de Saúde, scria reduzido ao de mera porta de entrada de um sistema unidimensionalmente concentrado na incorporação da assistência médica. Esta última, ao realizar uma verdadeira triagem dos problemas de saúde da população a partir do eixo "queixa/procedimento", dominaria totalmente o cenário, fomentando o risco de imprimir um aumento considerável de medica- lização da sociedade. Com o dominio da medicina curaliva na rede básica de serviços de saúde (que corresponde a cerea de $80 \%$ da totalidade dos scrviços prestados), a saúde pública e a medicina preventiva e social continuariam a desempenhar um papel secundário e submisso a uma postura que, ao nível tcórico não mais encontra meios de se legitimar.

Ao que tudo indica, portanto, o conjunto dos problemas apontados acima constitui um reforço considerável ao antigo paradigma positivista dominante que, ao camuflar a crise como uma mera questão administrativa/gerencial, ainda dá sinais de considerável vitalidade na manutenção de sua hegemonia. Explicar o motivo desta vitalidade é uma questão que extrapola a sua utilidade e mesmo a sua consistência cpistemológíca para penetrar na sua compatibilidade paradigmática com vários outros componentes de natureza política, social e cultural (Khun', 1975; Lakatos e Musgravc $^{7}, 1975$ ).

É somente na experiência prática que o paradigma social da medicina, ao compor-se com a sociedade mediante o desenvolvimento de políticas sociais apropriadas, pode aprimorar-se, estender o scu domínio e tornar-se real. Esta prática lhe permitiria tornar-se uma instância ativa de geração cultural que, ao difundir os seus princípios, receberia, ao mesmo tempo, suporte da comunidade e da sociedade mais ampla. A municipalização do sistema de saúde cm nível administrativo torna-se, sem dúvida, um campo mais fértil para que isso possa ocorrer. No entanto, um verdadeiro salto qualitativo fica ainda por se realizar para se chegar ao ponto de que efetivamente se cumpra o preceito constitucional da saúde (entendida como bemestar lísico, mental e social) como direito do cidadão c dever do Estado.

QUEIROZ, M. de S. \& VIANNA A.L. [The model of state healu policy and system of medical assistance adopled in present-day Brazill. Rev. Saúde públ., S. Paulo, 26: 132-40, 1992. A contribution to the analysis of the health reform presently occurring in Brazil is presented. The need to consolidate the theoretical background which supports the advances already achieved in order to understand recent events in the area is stressed. In this regard, the health reform is understood as a question transeending the mere administrative and managerial aspect of the health system, since it necessarily involves a redefinition of the concepts of health, disease and the medical practice adopled by the dominant mechanistic paradigm of medicine. The recent events which delineate the health system in Brazil are analysed and eriticised in the light of this concern.

Keywords: Health policy. Health system. National heallh programs. 


\section{Referênclas Bibliográficas}

1. AROUCA, S. O dilema preventivista: contribuição para a compreensão crítica da medicina preventiva. Campinas, 1975. [Tese de Doutorado - Faculdade de Ciências Médicas/UNICAMP].

2. CONFERENCIA Intemacional sobre Cuidados Primários de Saúde, Alma-Ata, 1978. Brasília, UNICEF, 1979.

3. DONNANGELO, M. C. F. \& PEREIRA, L. Sauide e sociedade. São Paulo, Ed. Duas Cidades, 1976.

4. EHRENRREICH, J. Introduction. In: Ehrenreich, J., ed. The cultural crisis of modern medicine. New York, Momphley Review Press, 1978.

5. ILLICH, I. A expropriação da saúde. Rio de Janciro, Ed. Nova Fronteira, 1975.

6. KHUN, T. S. A estrutura das revoluçôes cientificas. São Paulo, Perspectivas, 1975.

7. LAKATOS, I \& MUSGRAVE, A. La critica y el desarrol10 del conocimiento cientifico. Barcelona, Ed. Grijalbo, 1975.
8. O'NEAL, P. Heallh crisis 2000: WHO Report. London, Alden Press, 1983.

9. POWLES, J. On the limitations of modem medicine. Sci. Med. and Man, 1: 78-96, 1973.

10. SOMARRIBA, M. M. G. Comunity health and class society: the health programme of Norte de Minas, Brazil. Sussex, 1978. [Tese de Doutorado - University of Sussex].

11. TEIXEIRA, S. F. Reflexões teónicas sobre democracia e reforma sanitária. In: Teixeira, S. F., org. Reforma sa. nitária. São Paulo, Cortez Ed., 1989. p. 17-45.

12. VIANNA, A.L. Diagnóstico institucional: a política de saúde nos anos 80. Campinas, NEPP/UNICAMP, 1990. [Mimeografado].

Recebido para publicaçäo em 4/7/1991 Reapresentado em 11/12/1991 Aprovado para publicaçäo em 7/1/1992 